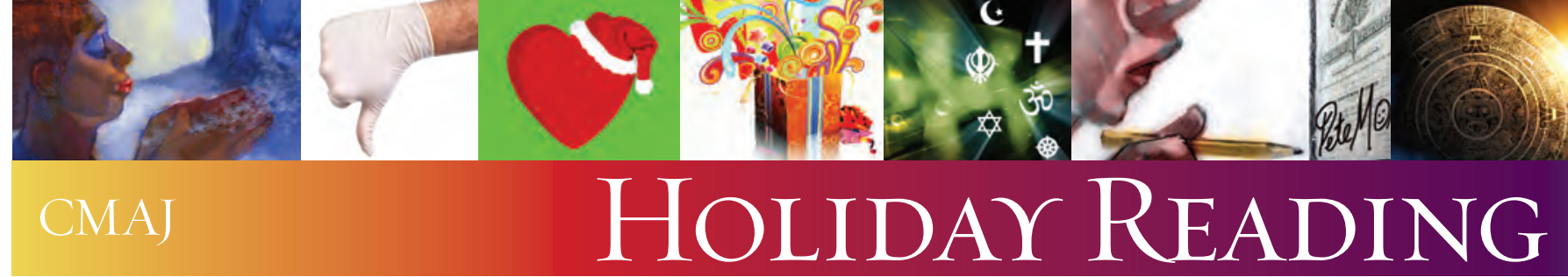

\title{
REFLECTIONS
}

\section{The little red box}

\section{Eric Cadesky MDCM}

I $\mathrm{t}$ was spring when I first met her at the clinic for refugees. Her translator arrived late, pressuring what little time we had together. She sat, calm and tranquil, while I spoke to her directly, looking into her emerald eyes. I wondered what she thought of me, a pale young man in a pale stiff coat, in a room with pale worn walls. Her translator listened intently while I spoke at length of diabetes and dialysis, relaying my entire speech in five terse Bengali words. Our game of broken telephone continued as she replied with a dignified nod of the head and a hushed "Mmmm," followed by her interpreter stating that "she agrees and she understands." Over the course of the next year she never disagreed and she never misunderstood.

The weather warmed and a routine emerged: our interactions crammed into rooms too small with time too short and words too few. A bindi sat in a central valley on her wrinkled forehead, protected by the neat nest of pinned gray hair above and the bushy clouds of her ashen eyebrows below, her wizened arms encircled with gold bands and covered by the silken waves of her sari. Occasionally, the wheel of my chair would catch the bottom of her garment and lead to embarrassed apologies, so certain was I to have wasted cultural sensitivity training with such egregious violations of personal space. I was too close physically, yet distressingly distant in every other way. I asked many questions: How is your energy? Have your sugars gone too high? Too low? With so much to discuss, I never seemed to have time for the important things. Despite her polite grins at the end of each visit, I wondered if I was helping at all.

The colours outside changed and the ground rustled with leaves. She returned with her translator, and I shared news from clinics and caregivers. Her translator spoke sparingly, and she replied with a nod in his direction, not mine. Was I now the third wheel? Through wounded pride or learned instinct, I asked the questions that I should have asked before: What was your life like back home? Are you happy here? After hearing the translation, she turned and peered at me. We held silent and steady for a few moments before she cast her eyes to the floor. The visit was over.

Jackets grew thicker and trees bare. Still paying off my student loan, I volunteered to cover the clinic during Christmas. We were busy, and I was tired, but the last minutes finally arrived before my holiday reprieve. As I was putting away my white coat, the secretary came in to tell me that a patient had arrived speaking neither English nor French, but carrying my business card. I walked to the waiting area where I found her. She looked

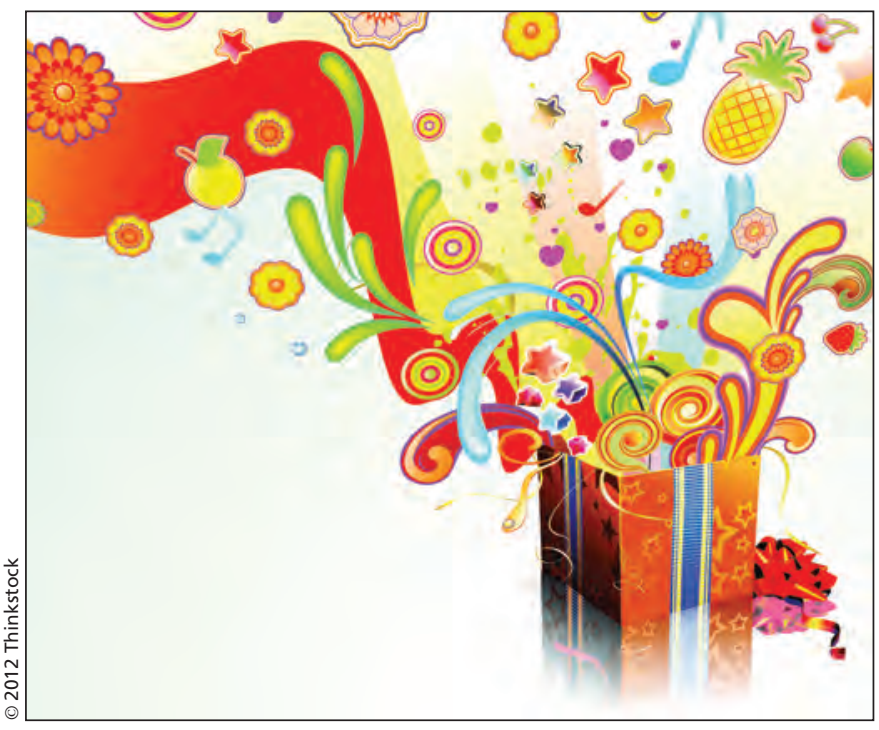

up at me with anxious eyes that relaxed when I motioned for her to follow. "Is your translator coming?" I asked, although I knew there would be no reply.

We slipped into a familiar room and took our places. She looked at me, then down to her hands cupping a small cloth bag decorated with an image of mistletoe. She moved it toward me. Inside was a red box, light and fragile, less than half the size of my palm. I had seen ones like it at the dollar store, its plastic beads now glittering like rubies. She watched my face with anticipation. I placed the box in a prominent place on my desk, met her gaze, smiling, and pressed my palms and fingers together as I bowed my head. Her face erupted into a sudden, joyous, cavernous smile. I'm not sure how long we smiled at one another, but I do know we were communicating directly for the first time.

That day was the happiest I had ever seen her, and accepting that small token was the best care I gave her. In addition to this simple present, she taught me to set aside my defenses as doctor and accept the vulnerable role of imperfect healer: the lesson I keep safe in a little red box.

Correspondence to: Eric Cadesky, eric.cadesky@gmail.com

Affiliations: Eric Cadesky is with the Department of Family Medicine, University of British Columbia, and the Louis Brier Home and Hospital, Vancouver, BC

CMAJ 2012. DOI:10.1503/cmaj.121613 